\title{
Influence of the English Language in Shaping Islamic Identity Among Religious Secondary School Students
}

Ahmad Taufik Hidayah b. Abdullah, Mohd Nazri b. Latiff Azmi, Engku Muhammad Tajuddin b. Engku Ali , Mohd Hazli b. Yah@Alias, Muzammir b. Anas, and Nur Izzati Suhaimi

Universiti Sultan Zainal Abidin (UniSZA), Terengganu, Malaysia

\section{Abstract}

Identity refers to how people understand their relationship to the world, how that relationship is constructed across time and space, and how people understand their possibilities for the future. This research examined some claims made that learners of the English language as a second language have associated themselves with the culture and practices of the native speakers thus eroding the identity of the learners as good Moslems. This research aimed at investigating this phenomenon, to what extent the changes existed, if any. The main topics to discuss were the influence of the English language towards religious secondary school students' identity and to what extent the students could retain their identity as Moslems. There was one theory employed in this research called Self-Identity Theory. 90 religious secondary students and 8 teachers were used as respondents by conducting focused group interviews and face to face interviews with them. They came from urban, sub-urban, elite and rural schools respectively. The findings revealed that there were mixed responses from the respondents on the issues. 85 students, making up $94.5 \%$ of the whole respondents, asserted that the English language did not change the students' Islamic identity. Meanwhile only 5 students, comprising $5.6 \%$ of the respondents, were of the opinion that the students had been influenced by the culture of native speakers of the English language thus eroding their identity as good Moslems. In a positive note, it was also found that there were some good values instilled in the teaching of the English language such as confidence, helping each other, teamwork, etc.

Keywords: self-identity, religious school, English language, Terengganu, Malaysia

\section{Introduction}

the responsibility of the AICLL

2019 Conference Committee.

Language is the primary source of communication. It is the method through which one shares their ideas and thought with others. Some people even say that language is what separates us from animals and makes us human. At the moment, there are thousands of languages in the world. Apart from some varieties of local languages spoken and understood by their people in different regions, countries usually have their own national 
languages. Language acquisition is essentially needed to sustain human socialization through communication towards one another. The language itself can literally support the continuity of human life in the work, business and education (Wijaya \& Nasution, 2018).

English was originally the language of England, but through the historical efforts of the British Empire, it has become the primary or secondary language of many countries that once colonized by the British colonies, such as Canada, Australia, India, the United States as well as Malaysia. At the moment English is used in many fields of life, from business to culture. As such, it is a very useful and necessary language to know and master in the world. And the English language is the most common foreign language in the world. For example, two people from two different countries usually use the English language as a common language to communicate.

Malaysia is one of the Asian countries that is adopting a bilingual system of education. The aim is to establish a balance between national and international needs and challenges manifested through linguistic educational policies (Gill \& Kirkpatrick, 2013). With reference to the Malaysian education system, the English language is placed as the second language and in line with the education policy, English language is made a compulsory subject at all levels of education. The English language is widely used in speaking, and sometimes official functions, as the language of politics, the media, jurisdiction, higher education and other such domains (Thirusanku \& Melor, 2012). Reflecting on the Malaysian pluralist society, the learners are commonly bilingual, trilingual or even multilingual.

In Malaysia, the Malay language is accepted to unite the culturally multilingual society of the Malaysian. On the other hand, the English language has a functional role because it is used as an international language of communication in the economy, thus, demonstrating its pervasive influence through its role in the education system. A good command of the English language among graduates will ensure employment and consequently will offer them to go global and international (Ramiza \& Peter, 2013).

In Malaysia, the establishment of Sekolah Menengah Agama or Islamic Religious Secondary Schools was in line with the modernization efforts of the National education system. The process of improving the Islamic education system in religious schools is in line with the current developments. Most religious secondary schools have prioritized Islamic Studies and Arabic but now have included mainstream subjects to their syllabus. One of the subjects taught is the English language. The religious secondary schools aim to educate students with Islamic personality, providing knowledge that fulfills worldly 
demands and hereafter, besides developing the potential of students in terms of interest, creativity, personality and leadership.

This research examined some claims made that learners of the English language as a second language have associated themselves with the culture and practices of the native speakers thus eroding the identity of the learners as good Moslems. This research aimed at investigating this phenomenon, to what extent the changes existed, if any. The main topics to discuss were the influence of the English language towards religious secondary school students' identity and to what extent the students could retain their identity as Moslems.

\section{Literature Review}

In the global world nowadays, there is no more the so-called border. People keep moving to enjoy better quality of life by migrating to find better jobs. So, the exodus of excellent brains from a developing country to a more advanced and developed country is nothing strange now. One of the factors enabling this migration is the ability of someone to speak a language that becomes the medium that can be understood by most parts of the globe. To shortlist among some of mostly spoken languages in the world, English language has its own role and pedigree due to its wide use in the world such as in economy, politics, culture, sports, etc. Our world nowadays does not seem to be able to link and communicate without this international language (Abdullah, 2018).

There is no doubt in the fact that English language has gained the status of the global language. It is spoken and taught in many countries as a native and a second or a foreign language. It is taught in schools, colleges, and universities in almost every country in the world. English is spoken by over 350 million people as their native language and about $\mathbf{2 5 0}$ million people around the world use it fluently as a foreign language. It is learnt that English language has been regarded as an international medium or passport in order to communicate with the entire world (Hossain, 2013).

Identity refers to how people understand their relationship to the world, how that relationship is constructed across time and space, and how people understand their possibilities for the future (Norton, 1997). Identity is a crucial non-cognitive factor that influences adolescents' classroom behavior and attitudes toward schooling (FloresCrespo, 2007; Hejazi, Lavasani, Amani, \& Was, 2012). Adolescence is a very important period of identity formation, during which young people are given opportunities to explore their own identities as they relate to their own interests, goals, and talents and negotiate with the standards of their social environments (Good \& Adams, 2008). 
One theory employed in this study is called Self-Identity Theory. According to SelfIdentity Theory, the word identity itself refers to continuity in a sense of self within a person, and the word also refers to how that person is socially regarded (Horowitz, 2012). The identity of a person, within a culture, is a topic of concern throughout the humanities, cognitive science, psychology, and psychoanalysis. In psychodynamic sciences, the complexity of multiple self-experiences and social presentations in an individual is addressed in terms of person schematization (Horowitz, 1991).

Although identity theory does focus more on behavior, it also draws upon underlying socio-cognitive processes such as reflected appraisals (McCall and Simmons, 1978), roletaking (Stryker, 1980), the definition of the situation (McCall \& Simmons, 1978; Stryker 1980), and self-verification and dissonance reduction (Burke, 1991a).

Scientists and linguists have conducted various studies and researches on how language shapes the way people think and behave. Language is a part of culture and culture has an effect on the way a person thinks, which initiates behaviors (Racoma, 2018). Culture is deemed as part of language and communication. However, that is not the same as culture being linked to a particular nation such as the UK and the US. For instance, the English language can be learnt in order to communicate and learn about other cultures from many aspects. It is noted that this can result in constructing new hybrid and liminal cultural groupings among the language users.

There was a research conducted to 200 students of Jahangirnagar University in Bangladesh where researchers sought to find out the impact and influence of the English language on the lifestyle of the tertiary level students in Bangladesh. The research analyzed the various ways in which the students of Jahangirnagar University used English language for various purposes. It also showed that the whole lifestyle of the student was affected by the English language (Hossain, 2013). Some findings were related to dressing style and eating habit of the students as the results of the English language which were elaborated below.

The research tried finding out if the dressing style of the students was influenced by the English language. It was thought of by some scholars of recent time that language carries culture and a language can have influence over other cultures. From the research, it was found that 171 students (85\%) thought that English language had no influence over Bangladeshi garment style. The rest of the respondents, however, thought otherwise. They showed that the English language had a kind of impact over Bangladeshi University students. They wore some dresses that were produced in the west. 
With regard to the influence of English language over the eating habit of Jahangirnagar university students, it was revealed that only 7.5 percent of the students thought that their eating habit was influenced by the English language and culture. Meanwhile, 184 students or 92 percent of the students found no influence of the English language over their eating habit and 1 student did not answer.

On another note, one lecturer of the Jahangirnagar University opined that English media played a very important role in learning English language and culture. And she added that speaking good English brought changes in the psychology of the students because it was a kind of sophistication to some of them and it created a kind of superiority complex among them. It was also seen that almost all the teachers agreed that the English language created a kind of superiority complex among the students. (Hossain, 2013).

\section{Research Method}

Design of this research employed qualitative approach where 90 religious secondary students and 8 teachers in the state of Terengganu, Malaysia were used as respondents. Focused group interviews were conducted with the students, meanwhile face to face interviews were conducted to the teachers. They came from one urban school, one sub-urban school, one elite school and two rural schools. All of the five schools were from the Islamic religious secondary schools. By gender, the respondents consisted of 39 male students and 51 female students.

The focused group interviews were conducted to 90 students from 5 religious secondary schools by 5 researchers from Universiti Sultan Zainal Abidin, Malaysia where a semi-structured interview was carried out. Interview sessions were conducted in a separate session between male students and female ones as a common practice in an Islamic religious secondary school to solicit and disseminate information from the respondents. Meanwhile, face to face interviews were conducted with each school's language coordinator. They were either from English language teacher or Arabic language teacher. For the purpose of this research, answers from the English language teachers were mostly used in order to meet the research objectives. All collected data were transcribed and analyzed using thematic analysis. 


\section{Result and Discussion}

Research findings or results of this research are described and explained in line with the questions posed during the focused-group interviews to 90 religious secondary school students. Meanwhile research findings and results of face to face interviews with 5 teachers are also described based on the questions posed. For easy reporting and explaining purposes, all items or questions are numbered. Subsequently, some discussion is given to shed light on the phenomenon being discussed.

\subsection{Focused group interviews with 90 students}

\subsubsection{Focused group interviews with 90 students}

When posed with the first question as to their reasons to enroll in the religious secondary school, most of the students answered that it was mostly their own choice besides the request of parents who wished to have children excelling in both academic and Islamic religion. Most of them have already known some information on the environment of the religious schools that was highly Islamic thus making it a conducive place for learning. The situation and environment help them in their studies, including the learning of the language studies, be it in the Arabic language or in the English language.

Other reasons for the students to enroll in the religious secondary schools are: they believe that the religious schools are respected by the society, especially in the state of Terengganu where majority of their population are Moslems. Besides, most of the students have been familiar with Islamic studies or Arabic language studies when they are still in the primary schools. Their familiarity with the Islamic and Arabic language subjects, coupled with their Islamic environment in their own life has resulted in them choosing to enter the religious schools and that is a mutual choice both by the students and their parents.

\subsubsection{To what extent both students and instructors understand the ele- ments of self-identity in relation to learning of a language.}

On the first question posed to the students on the meaning or notion of "self-identity", they came up with varied answers. Some responded that self-identity has something to do with attitude, personality, opinion, and self-confidence, principle of life, moral, belief, pride, courage, leadership, and vision. 
There are some manifestations in relation to the self-identity among the students such as: never failed to perform their prayers, respecting others, helping each other, always be polite to people, covering their private parts that cannot be exposed. They also insisted on sticking to the Islamic values and teachings due to some reasons such as from the knowledge they learnt at school, their self-awareness in keeping their good image, to be closed to Allah-God the Almighty, encouragement from their parents and the Islamic environment of their school. They believed that the school where they are studying now helps them shape their self-identity towards more Islamic.

On a specific question, when the students were provoked with a question whether they felt proud if they could speak English well, most of the respondents answered that they were very proud of it, some proud of being praised by others too. This feeling was in line with the self-identity theory (Horowitz, 2012) and reflection of appraisals (McCall and Simmons, 1978), role-taking (Stryker, 1980). They also had good and kind heart to help others who need help in their English language. They also felt that they should not behave or feel like someone from the UK or from the USA in terms of speaking or dressing. They felt that they were keen to learn the language without having the intention to change their culture, dressing or personality. They still felt that they were from the Malay root who wanted to maintain their own Malay culture.

\subsubsection{To what extent the syllabus in the language subject contains ele- ments of self-identity.}

Most students asserted that the language they studied also influence their way of life and self-identity. They opined that when learning a language, students need to know the origin of the language, the original users of the language as well as their culture. However, they believed that students must be selective and smart in filtering the good and bad influences of the culture of the language that they are studying in order to contain some bad influence towards the local Moslems.

On the assumptions that learning English language can make someone trapped and influenced by bad influence of the culture of the native speakers, 85 students $(94.5 \%$ from the whole respondents) disagreed with the statement by leaving it back to each individual. Any language, be Arabic or English language are only languages. It is the person that should filter and subsequently follow the good lessons from each language. If there are bad cases involving students who are good in the English language, the culprit should not be towards the English language itself. It may be caused by the students who happen to be lack of Islamic knowledge and it has nothing to do with the 
English language. These group of respondents think that the English language is very important and needed in order to gain knowledge since a lot of books are translated into the English language.

On a specific question asking respondents on learning the English language in relation to their self-identity for being a good female Moslem, they seemed to have varied answers. Some respondents were realistic and pragmatic by giving an example of the use of social media as platform like YouTube in watching Islamic contents such as a talk on religion or a forum. They opined that they could learn two things at one time, learning contents of Islamic teaching and the English language if the programme is delivered in the English language, especially if the person giving talks is an Englishnative speaker. However, 5 students (5.6\% of the respondents) were a bit skeptical about the English language and asserted that the English language can make them go astray or less Islamic in terms of social life, attitude and appearances.

When comparing the perception that the learning of the Arabic language can lead and shape someone to be more Islamic and the English language cannot, the students also had some split opinions. Most of them opined that the statement was merely a perception. They gave an analogy that students who learned the English language and good at the language but they had strong Islamic knowledge and background can make him or her a good person in the English language as well as having strong self-identity as a devout Moslem. Likewise, it is not guaranteed that the students who learn the Arabic language will automatically make her or him a good Moslem.

\subsubsection{If any improvements are needed in the syllabus of the religious secondary schools to uplift the element of self-identity especially in learning the English language.}

Many students feel that the syllabus should be improved and revamped by including more figures and characters from the Islamic world but written in the English language. For example, they proposed to include more outstanding figures or heroes from the Islamic world of the past and today to be included in the English language text books. This will increase the interest of the readers to read the English text books or literature.

But the students are also of the opinion that there have been some values of selfidentity applied in the teaching and learning of languages learnt at school, be it in the Malay language, the Arabic language and the English language. Some of the good values of self-identity exposed are: helping each other, teamwork, physical and mental fortitude, being fit in life, how to build self-confidence via presentations and there is 
the gut to talk to the native speakers of the foreign languages. On specific note, some students asserted the importance of including element of leadership in the teaching and learning to enable this country to produce their future leaders that can lead the country.

On a specific note, a sizeable number of respondents are of the opinion that there are some good values of self-identity applied in the teaching of English language in the class room such as to stimulate and encourage students to speak in the English language, have a courage to answer in the class room using the English language. Some students also suggested to have outdoor English camp involving students from other schools and if possible, to involve English native speakers as facilitators since in the state of Terengganu, Malaysia there was a special programme arranged by the state government to bring in young English teachers from the USA to teach at some selected secondary schools in Terengganu, Malaysia. Besides, they also proposed to gazette "English speaking Day" for certain days in a week at school to encourage the students to speak the English language.

\subsubsection{Role and preparation of instructors and school administrators in applying patriotism values in the education system.}

The students are of the opinion that the teachers, especially the English language instructors, play their important role since the students needed a role model to emulate since most of the students' time was in school. Some students were a bit critical about their teachers' dressing codes during class time. They observed that many female Arabic language teachers wore long scarf to cover their head and instilled in the Islamic values in their lessons, meanwhile Malay language teachers and English teachers did not wear long scarf and did not insert much Islamic knowledge in their lessons.

In short, the teachers are very important in shaping the self-identity of their students at schools. The influence of the teachers towards the students, especially towards female students, is very great through their appearance and delivery in the class room, including during the teaching and learning of the English language.

\subsection{Face to face interviews with 8 teachers of the religious sec- ondary schools}




\subsubsection{Influence of the English language towards the students' self- identity.}

In general, two foreign languages were given due emphases at the religious secondary schools, they were the Arabic language and the English language besides the Malay language as the national language. It was noted that at the elite religious secondary school, most students were more proficient and fluent in using the English language compared to the Arabic language.

One teacher was of the opinion that the students who were good at the English language could have good behaviors in their life, they could behave well and did not emulate some bad values or characters from the cultures of the English native speakers. She asserted that these students were active and it was manifested in their characteristics where they were more outspoken and had a high self-confident level.

\subsubsection{Improvement that needs to be made in the school's language syllabus.}

The school syllabus, especially in the teaching of languages, also include some good values including to build one's self identity. However, the time and application of the good values were sometimes seasonal or on certain time only. For example, to instill in the value of patriotism, it was only stressed and encouraged during the month of the Independence Day celebration but was given less attention during other months. This value needed to be instilled every now and then to make them more patriotic to their homeland and country.

Another room for improvement is on the use of English language text books. The teaching and learning of the English language now is using Common European Framework of Reference for Language (CEFR) with many sources from the UK. Text books for form 1 and form 2 students were fully from the UK including the contents, and setting in the UK. To some students, they found it rather difficult to familiarize themselves with the contents and settings. Some of them might be disappointed but the teachers had guided on how to use the books. However, some students still found them rather difficult.

Fortunately, some students in the state of Terengganu now can get books from the Terengganu Royal Foundation that cater to the students for teaching contents with the settings and context of the local setting and environment in Terengganu. The students 
had enjoyed themselves learning with contents of the local thus indirectly preserving the treasures of our country and strengthening the self-identity of our students.

\subsubsection{Teachers' observations on students who are good in the English language}

Most teachers observed that the students who were good at the English language would have more self-confidence in themselves compared to students who were not that so good. The good students in English would feel more confident when they spoke and it was very obvious that these students liked to try new things. These students could give more positive impacts to themselves as well as to others.

It was also seen that the students who were good at the English language would involve in many activities at schools such as debates, lectures, etc. Although these students were active users of the English language, they still could retain and maintain their self-identity as local Malay students who rooted their culture and religion basis.

On a sad note, one teacher noted that there was a skeptic remark among the students or learners that jokingly considered the English language as a colonizer language. In her observation, she opined that these group of students were just a bit lack of confident in speaking the language thus refusing to learn and speak in the English language.

\section{Conclusion}

The research concluded that there were mixed responses from the respondents on the issues of the influence of the English language towards students of religious secondary schools in the state of Terengganu in Malaysia in conjunction with their identity as Moslems. Majority asserted that the English language did not change the students' identity, meanwhile, only a small section of respondents thought that the students had been influenced by the culture of the English language. There were some positive notes in the build-up of self-identity among students who can speak English language well in conjunction with the self-identity theory where they feel proud of being able to speak English well as part of appraisal from others and recognition of their ability. Besides, it was also found that there were some good values instilled in the teaching of the English language such as confidence, helping each other, teamwork, etc. 


\section{References}

[1] Abdullah, A.T.H. (2018). The Roles of Anxiety and Motivation in English Public Speaking among Undergraduates at Univrsiti Sultan Zainal Abidin, Malaysia. Unpublished PhD Thesis. Universiti Sultan Zainal Abidin, Indonesia.

[2] Burke, P.J. (1991a). Identity Processes and Social Stress. American Sociological Review, Volume 56, No. 6, 836-49. doi: 10.2307/2096259

[3] Flores-Crespo, P. (2007). Ethnicity, identity and educational achievement in Mexico. International Journal of Educational Development, 27, 331-339.

[4] Gill, S.K., \& Kirkpatrick, A. (2013). English in Asian and European Higher Education. In C. A. Chapelle (Ed.), The Encyclopaedia of Applied Linguistics. Oxford: UK: Blackwell Publishing Ltd.

[5] Good, M., \& Adams, G. R. (2008). Linking academic social environments, ego-identity formation, ego virtues, and academic success. Adolescence, 43 (170), 221-236.

[6] Hejazi, E., Lavasani, M.G., Amani, H., \& Was, C.A. (2012). Academic identity status, goal orientation, and academic achievement among high school students. Journal of Research in Education, 22, 294-318.

[7] Horowitz, M.J. (1991). Person schemas and maladaptive interpersonal patterns. Chicago: University of Chicago Press.

[8] Horowitz, M.J. (2012). Self-Identity Theory and Research Methods. Journal of Research Practice, Volume 8, Issue 2.

[9] Hossain, M.D. (2013). The Impact of English Language on the Lifestyle and Behavior of Tertiary Level Students in Bangladesh: Case Study Jahanginagar University. Global Journal of Human Social Science, Linguistics \& Education. Volume 13, Issue 10.

[10] McCall, G J., \& Simmons, J.L. (1978). Identities and Interactions. New York: The Free Press

[11] Norton, B. (1997). Language, Identity, and the ownership of English. TESOL Quarterly, Vol. 31, No. 3, 409-429.

[12] Racoma, B. (2018). Language Shapes the Way People Think and Behave. Retrieved on 30 April 2019 from https://www.daytranslations.com

[13] Ramiza, D., \& Peter, A. (2013). Exploring language anxiety of Malaysian learner. Paper presented at the 2nd Malaysian Postgaduate Conference (MPC) 2012, Bond University Gold Coast, Queensland, Australia.

[14] Stryker. (1980). Symbolic Interactionism: A Social Structural Version. Menlo Park: Benjamin Cummings. 
[15] Thirusanku, J., \& Melor, M.Y. (2012). The many faces of Malaysian English. International Scholarly Research Network. doi: 10.5402/2012/138982.

[16] Wijaya, L., \& Nasution, N.S.S. (2018). Language as Art and Communication Tool. In The 1st Annual International Conference on Language and Literature, KnE Social Sciences,. doi: 10.30743/aicll.v1i1.10 